\title{
ANALISIS METODE ANTRIAN PASIEN PESERTA BPJS PADAPUSKESMAS DI WILAYAH KOTA BEKASI SELATAN (STUDI KASUS: UPTD PUSKESMAS PEKAYON JAYA)
}

\author{
Oleh: \\ Siti Juriah \\ Program Studi Pendidikan Ekonomi \\ Fakultas Ilmu Pendidikan dan Pengetahuan Sosial \\ Universitas Indraprasta PGRI \\ Email: \\ Sitijuriah336@gmail.com
}

\begin{abstract}
ABSTRAK
Tujuan dari penelitian ini untuk mengetahui system antrian yang saat ini digunakan oleh UPTD Pekayon Jaya, Bekasi. Metode yang digunakan dalam penelitian ini adalah metode penelitian deskriptif dengan pendekatan kuantitatif. Berdasarkan hasil penelitian dapat disimpulkan bahwa model struktur antrian yang diterapkan oleh Puskesmas Pekayon Jaya adalah multi channel-multi phase sedangkan proses pelayanan antrian pasien BPJS yang digunakan adalah single channel-multi phase. Hasil perhitungan yang sudah dilakukan dengan menggunakan rumus metode antrian terhadap data pasien BPJS pada Puskesmas Pekayon yang diteliti mulai tanggal 18 Oktober-17 November 2017 dan 18 November-16 Desember 2017 antara jam 08.00-15.00 WIB. Tingkat kedatangan rata-rata per jam 8 orang/jam dan 12 orang, tingkat pelayanan rata-rata 18 orang/ jam dan 18 orang/jam. Ratio pelayanan Puskesmas Pekayon Jaya 44\% dan 70\%, probabilitas tidak ada antrian $33 \%$ dan $17,6 \%$. Waktu rata-rata pasien menunggu dalam antrian 3 dan 6 menit. Waktu rata-rata setiap pasien berada dalam system keseluruhan (waktu menunggu plus waktu pelayanan) 7 dan 10 menit.
\end{abstract}

Kata kunci: Metode antrian, Multi Channel-Single Phase, Puskesmas

\begin{abstract}
The purpose of this study is to find out the queuing system currently used by the UPTD Pekayon Jaya, Bekasi. The method used in this study is a descriptive research method with a quantitative approach.Based on the results of the study it can be concluded that the queuing structure model applied by the Pekayon Jaya Health Center is multi-channel - multi-phase while the service process for the queue of BPJS patients used is single channel - multiphase. The results of calculations that have been done using the queuing method formula for BPJS patient data at the Pekayon Community Health Center studied from October 18 to November 17, 2017, and November 18 to December 16, 2017, between 08.00$15.00 \mathrm{WIB}$. The average arrival rate per hour is 8 people/hour and 12 people, the
\end{abstract}


average service level is 18 people/hour and 18 people/hour. The ratio of Pekayon Jaya Health Center services is $44 \%$ and $70 \%$, the probability of no queues is $33 \%$ and $17.6 \%$. When the average patient waits in queues 3 and 6 minutes. The average time for each patient is in the whole system (waiting time plus service time) 7 and 10 minutes.

Keywords: Queue method, Multi-Channel - Single Phase, Puskesmas

\section{A. PENDAHULUAN}

Aktivitas antrian adalah bagian dari kehidupan kita sehari-hari, antrian yang panjang selain menjadi tidak efektif juga menjadi salah satu alasan terbuangnya waktu kita. Waktu yang seharusnya dapat digunakan untuk melakukan hal lain. Salah satu antrian yang sering kali terjadi adalah di pusat pelayanan kesehatan, klinik kesehatan, puskesmas dan rumah sakit. (Sumber: Warta Kota, 2017).

Puskesmas adalah sebuah instansi pelayanan masyarakat yang harus memberikan pelayanan yang terbaik bagi masyarakat, semenjak adanya Badan Penyelenggara Jaminan Sosial (BPJS) kesehatan membuat puskesmas kewalahan dalam mengatasi penumpukan antrian pasien (Larasati, 2013; Rakhmawati \& Rustiyanto, 2016) hal ini menyebabkan ketidaknyamanan pada pelayanan puskesmas tersebut (Anshory, 2013).

Antrian yang terjadi di pusat pelayanan kesehatan dapat disebabkan beberapa faktor salah satunya adalah kurangnya petugas pelayanan pengambilan nomor antrian, jumlah tenaga medis dan pasien yang tidak sebanding juga menjadi salah satu menyebab terjadinya antrian (Sumber: Metrosindonews, 2017)

Puskesmas yang ada di wilayah Kota Bekasi adalah sebanyak 39 Puskesmas, dengan 2 Puskesmas terakreditasi dan 37 Puskesmas non akreditasi (Sumber: Metrosindonews, 2017). Puskesmas yang menjadi objek penelitian adalah Puskesmas di wilayah Kota Bekasi Selatan yaitu UPTD Puskesmas Pekayon Jaya. Berbagai pelayanan kesehatan dasar yang dilaksanakan oleh fasilitas pelayanan kesehatan adalah sebagai berikut:
a) Pelayanan ibu dan bayi
b) Pelayanan antenatal (K1 \& K4)
c) Pelayanan ibu nifas
d) Pelayanan Keluarga Berencana (KB)
e) Pelayanan imunisasi
f) Pelayanan kesehatan gigi
g) Pelayanan kesehatan lansia

Program pokok yang telah diselenggarakan di Puskesmas adalah sebagai berikut:

a) Program Promosi Kesehatan

b) Program Kesehatan Lingkungan

c) Program Kesehatan Ibu dan Anak serta Keluarga Berencana

d) Perbaikan gizi masyarakat

e) Program pencegahan dan pemberantasan penyakit menular

f) Pengobatan 
Berdasarkan pemaparan diatas, kami mencoba melakukan penelitian mengenai metode antrian pasien peserta BPJS di UPTD Puskesmas Pekayon Jaya.

\section{B. KAJIAN PUSTAKA}

\section{Pengertian Teori Antrian}

Menurut (Hillier \& J, 2001, p. 834), Queueing theory is the study of waiting in all these various guises. It uses queueing models to represent the various types of queueing systems (systems that involve queues of some kind) that arise in practice.

Menurut (Taha, 2007, p. 550), Waiting cannot be eliminated completely without incurring inordinate expenses, and the goal is to reduce its adverse impact to "tolarable" levels.

Menurut (Hillier \& J, 2001, pp. 835-836), salah satu karakteristik dari sumber input adalah ukurannya. Ukuran adalah jumlah total konsumen yang mungkin membutuhkan pelayanan dari waktu ke waktu, sebagai contoh adalah jumlah total konsumen potensial yang berbeda. Ukurannya dapat dianggap tidak terbatas atau terbatas. Karena perhitungannya lebih mudah untuk kasus tidak terbatas, asumsi ini sering digunakan bahkan ketika ukuran aktual lebih besar dari pada jumlah terbatas dan harus dianggap sebagai asumsi implisit untuk setiap model antrian yang tidak menyatakan hal yang sebaliknya.

\section{Tipe Sumber Populasi}

Sumber populasi merupakan alat dari mana objek yang akan dilayani berasal. Sumber dimaksud dibedakan menjadi 2 yaitu:

\section{a. Infinite Source Model}

Tipe ini merupakan model sumber unit analisis antrian dengan objek yang datang meminta pelayanan pada fasilitas layanan jumlahnya tidak tentu (bersifat acak). Kedatangan ke dalam sistem untuk meminta pelayanan bersifat random. Objek akan tiba dengan jadwal yang tidak ditentukan. Oleh karena itu terdapat kemungkinan pada jam tertentu tidak ada dan pada jam yang lain pelanggan berdatangan dengan jumlah yang banyak. Gejala kedatangan yang bersifat acak ini menjadi penyebab terjadinya antrian dalam pelayanan.

\section{b. Finite Source Model}

Tipe ini merupakan model dengan sumber unit antrian yang datang meminta pelayanan pada fasilitas layanan adalah tertentu atau terdefinisi jumlahnya. Sumber populasinya diketahui dengan pasti. 


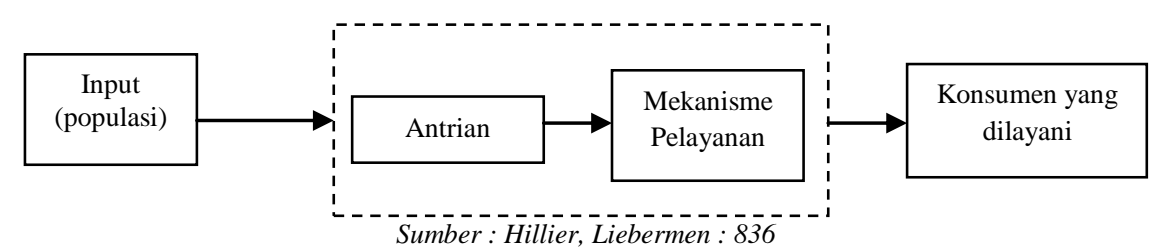

Gambar 1.

Dasar Proses Antrian

\section{Tipe Struktur Antrian}

a. $\quad$ Single Channel, Single Phase Model (SC-SP)

Adalah sistem pelayanan yang hanya memiliki satu saluran pelayanan dan jasa yang diberikan akan selesai atau sempurna pada satu tahapan saja.

b. Multi Channel, Single Phase Model $(M C-S P)$

Merupakan penggandaan dari sistem yang pertama, jasa yang diberikan hanya selesai dalam satu tahap saja, tetapi tenaga pelayanan lebih daripada satu.

c. Single Channel, Multi Phase Model (SC-MP)

Sistem pelayanan yang hanya memiliki satu saluran pelayanan, tetapi jasa yang diberikan akan selesai dalam beberapa tahapan.

d. Multi Channel, Multi Phase Model (MC-MP)

Sistem yang memberikan jasa pelayanan yang akan selesai dalam beberapa tahapan, dengan petugas pelayanan lebih dari satu barisan atau lebih dari satu pelayanan.

e. $\quad$ Mixed Phase, Single to Multi Phase

Struktur campuran dengan tahapan yang bersifat pilihan, dengan sebuah sistem pelayanan yang menyediakan jasa single - phase dan multiphase.

f. Mixed with Alternative Phase

Struktur campuran dengan tahapan yang bersifat pilihan, dengan sebuah sistem pelayanan yang menyediakan jasa single - phase dan multiphase.

\section{Macam - macam aturan antrian}

a. FIFO: First In First Out

Kedatangan pelanggan pertama menerima pelayanan pertama.

b. LIFO: Last In First Out

Kedatangan terakhir menerima pelayanan lebih dulu.

c. Random (acak)

Penerimaan pelayanan secara acak. 


\section{METODE PENELITIAN}

\section{Pendekatan Penelitian}

Penelitian dilaksanakan pada UPTD Puskesmas Pekayon Jaya di Wilayah Kota Bekasi Selatan. Adapun waktu pelaksanaan penelitian mulai Bulan November 2017 sampai dengan Bulan Desember 2017. Penelitian ini menggunakan pendekatan kuantitatif.

Menurut (Muslich, 2010, p. 11), "Metode kuantitatif adalah satu metode pengambilan keputusan manajerial untuk memecahkan masalah yang dihadapi dalam suatu sistem manajemen." Sedangkan menurut (Sugiyono, 2011, p. 7), metode penelitian kuantitatif dapat diartikan sebagai metode penelitian yang berlandaskan pada filsafat positivisme, digunakan untuk meneliti pada populasi atau sampel tertentu, pengumpulan data menggunakan instrument penelitian, analisis data bersifat kuantitatif/statistik, dengan tujuan untuk menguji hipotesis yang telah ditetapkan. Menurut (Arikunto, 2013, p. 2) ada 3 cara penelitian dilakukan yaitu:

1. Description Research atau penelitian deskripsi

2. $\quad$ Operation Research atau action research

3. Experimen atau eksperimen

Pada penelitian kali ini, peneliti menggunakan penelitian dengan cara Operation Research. Operation research menunjuk pada kegiatan yang sedang berlangsung, penelitian yang dilakukan bukan menciptakan yang baru semata, tetapi menempel pada suatu kegiatan yang berlangsung.

Menurut (Arikunto, 2013, p. 8),"Operation Research adalah suatu penelitian yang dilakukan oleh seseorang yang bekerja mengenai apa yang ia laksanakan tanpa mengubah sistem pelaksanaannya."

Perhitungan diperoleh melalui pengolahan data dengan menggunakan metode antrian yang terjadi di lapangan (Puskesmas Pekayon Jaya) lalu menganalisis apakah antrian tersebut sudah efesien atau kurang efisien.

Analisis yang diperoleh dari penelitian ini akan dijelaskan secara deduktif.

\section{Teknik Pengumpulan Data}

Teknik pengumpulan data yang digunakan adalah:

a. Wawancara tidak terstruktur

Wawancara yang pertama kali kami lakukan adalah dengan Kepala Puskesmas, hal ini dikarenakan kami membutuhkan gambaran umum dari operasional Puskesmas, berapa banyak staf dan pasien yang datang ke Puskesmas. Pada hari dan jam berapa tingkat antrian cenderung tinggi dan rendah.

b. Observasi Non partisipan

Peneliti mengamati perilaku pasien peserta BPJS dan staf Puskesmas dalam operasional sehari - hari. Peneliti mencatat setiap kegiatan dan menghitung waktu tunggu dari pasien pertama ke pasien berikutnya sampai dengan pasien terakhir. Waktu observasi dilakukan mulai pukul $07.00 \mathrm{sd} 15.00 \mathrm{WIB}$. 


\section{HASIL DAN PEMBAHASAN}

1. Model Struktur Antrian

Hasil observasi model struktur antrian yang diterapkan oleh Puskesmas Pekayon Jaya adalah multi channel - multi phase seperti yang ditunjukkan pada gambar di bawah ini:

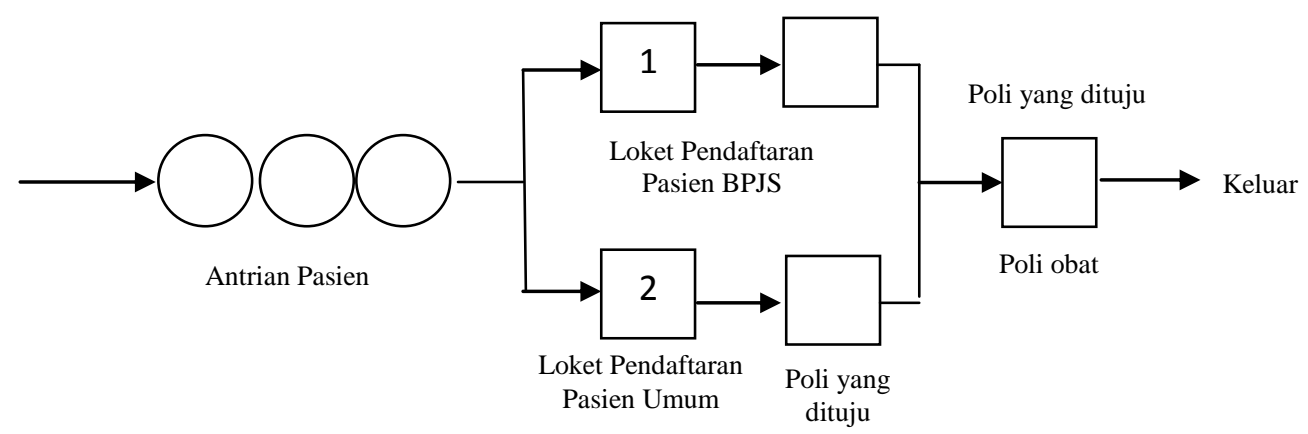

Gambar 2. Sistem Antrian di Puskesmas Pekayon Jaya

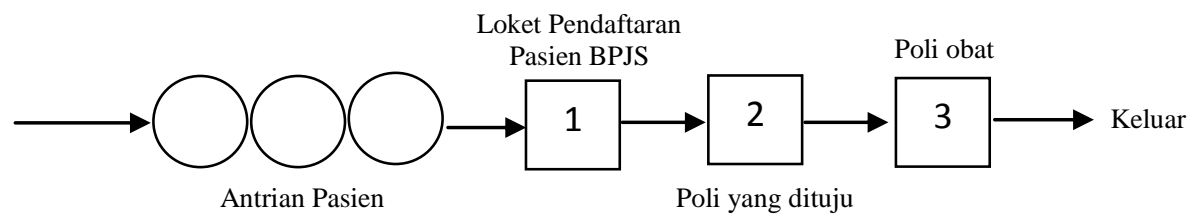

Gambar 3. Sistem Antrian di Puskesmas Pekayon Jaya

Sedangkan proses pelayanan antrian pasien BPJS yang digunakan oleh Puskemas Pekayon adalah single channel multi phase, seperti ditunjukkan pada gambar dibawah ini :

2. Pola Kedatangan dan Durasi Pelayanan

Tabel 1.

Pola Kedatangan Pasien Puskesmas Pekayon Jaya 18 November - 16 Desember 2017

\begin{tabular}{cccc}
\hline Tanggal & Jumlah Pasien & Tanggal & Jumlah Pasien \\
\hline \hline $18 / 11 / 2017$ & 81 & $02 / 12 / 2017$ & 82 \\
$20 / 11 / 2017$ & 84 & $04 / 12 / 2017$ & 79 \\
$21 / 11 / 2017$ & 88 & $05 / 12 / 2017$ & 84 \\
$22 / 11 / 2017$ & 87 & $06 / 12 / 2017$ & 83 \\
$23 / 11 / 2017$ & 85 & $07 / 12 / 2017$ & 89 \\
$24 / 11 / 2017$ & 84 & $08 / 12 / 2017$ & 85 \\
$25 / 11 / 2017$ & 87 & $09 / 12 / 2017$ & 84 \\
$27 / 11 / 2017$ & 90 & $12 / 12 / 2017$ & 89 \\
$28 / 11 / 2017$ & 88 & $13 / 12 / 2017$ & 80 \\
$29 / 11 / 2017$ & 86 & $14 / 12 / 2017$ & 83 \\
$30 / 11 / 2017$ & 83 & $15 / 12 / 2017$ & 82 \\
$01 / 12 / 2017$ & 87 & $16 / 12 / 2017$ & 86 \\
\hline
\end{tabular}


Tabel 2.

Pola Durasi Pelayanan Pasien Puskesmas Pekayon Jaya 18 November - 16 Desember 2017

\begin{tabular}{cccc}
\hline Tanggal & Durasi Pelayanan & Tanggal & Durasi Pelayanan \\
\hline \hline $18 / 11 / 2017$ & $0: 03: 23$ & $02 / 12 / 2017$ & $0: 03: 28$ \\
$20 / 11 / 2017$ & $0: 03: 27$ & $04 / 12 / 2017$ & $0: 03: 16$ \\
$21 / 11 / 2017$ & $0: 04: 13$ & $05 / 12 / 2017$ & $0: 03: 11$ \\
$22 / 11 / 2017$ & $0: 04: 01$ & $06 / 12 / 2017$ & $0: 03: 17$ \\
$23 / 11 / 2017$ & $0: 03: 30$ & $07 / 12 / 2017$ & $0: 04: 03$ \\
$24 / 11 / 2017$ & $0: 03: 15$ & $08 / 12 / 2017$ & $0: 03: 21$ \\
$25 / 11 / 2017$ & $0: 03: 17$ & $09 / 12 / 2017$ & $0: 03: 28$ \\
$27 / 11 / 2017$ & $0: 04: 06$ & $12 / 12 / 2017$ & $0: 04: 15$ \\
$28 / 11 / 2017$ & $0: 02: 59$ & $13 / 12 / 2017$ & $0: 03: 27$ \\
$29 / 11 / 2017$ & $0: 03: 04$ & $14 / 12 / 2017$ & $0: 03: 19$ \\
$30 / 11 / 2017$ & $0: 03: 08$ & $15 / 12 / 2017$ & $0: 03: 14$ \\
$01 / 12 / 2017$ & $0: 04: 11$ & $16 / 12 / 2017$ & $0: 03: 18$ \\
\hline
\end{tabular}

a. Tingkat kedatangan rata - rata per hari $(\lambda)$

1) Tanggal 18 Oktober - 17 November 2017:

$$
\frac{1539}{27}=57 \text { orang }
$$

2) Tanggal 18 November - 16 Desember 2017:

$$
\frac{2036}{24}=84,8 \text { orang per hari }
$$

b. Tingkat kedatangan rata-rata per jam $(\lambda)$

1) Tanggal 18 Oktober - 17 November 2017:

$$
\frac{57}{7}=8,14 \sim 8 \text { orang }
$$

2) Tanggal 18 Oktober -17 November 2017:

$$
\frac{85}{7}=12,14 \sim 12 \text { orang }
$$

c. Rata - rata jumlah yang dilayani per jam $(\pi)$

1) Tanggal 18 Oktober-17 November 2017:

$$
\frac{60}{03.28}=18,29 \sim 18 \text { orang }
$$

2) Tanggal 18 November - 16 Desember 2017:

$$
\frac{60}{03.39}=17,69 \sim 18 \text { orang }
$$




\section{Analisis Sistem Antrian Dengan Perhitungan Nilai-Nilai Numerikal}

1. Proporsi waktu rata-rata yang diperlukan petugas Puskesmas untuk melayani pasien atau faktor (tingkat) kegunaan $(\mathrm{P})$ :

$$
\mathrm{P}=\frac{\lambda}{\mu}
$$

2. Probilitas tidak ada pasien dalam sistem keseluruhan (Po):

$$
P_{o}=1-\frac{\lambda}{\mu}
$$

3. Proporsi waktu rata-rata pasien menunggu dalam antrian (LQ):

$$
L Q=\frac{\lambda^{2}}{\mu(\mu-\lambda)}
$$

4. Jumlah rata - rata pasien berada di dalam sistem keseluruhan (menunggu plus yang sedang dilayani) (LS):

$$
\mathrm{LS}=\frac{\lambda}{\mu-\lambda}
$$

5. Waktu rata - rata pasien menunggu dalam antrian (WQ):

$$
W Q=\frac{\lambda}{\mu(\mu-\lambda)}
$$

6. Waktu rata - rata setiap pasien berada dalam sistem keseluruhan (waktu menunggu plus waktu pelayanan) (WS):

$$
W Q=\frac{1}{\mu-\lambda}
$$

Tabel 3.

Analisis Sistem Antrian dengan Perhitungan Nilai - Nilai Numerikal

\begin{tabular}{ccc}
\hline IndikatorPenguat & $\mathbf{1 8}$ Nov - 17 Nov & $\mathbf{1 8}$ Nov - 16 Des \\
\hline \hline P & 0,44 jam atau 26,7 menit & 0,70 jam atau 42 menit \\
Po & 0,55 jam atau 33,3 menit & 0,29 jam atau 17,6 menit \\
LQ & 1 pasien & 1 pasien \\
LS & 1 pasien & 2 pasien \\
WQ & 3 menit & 7 menit \\
WS & 6 menit & 10 meniit \\
\hline
\end{tabular}




\section{E. SIMPULAN}

Aturan pada antrian di loket Puskesmas Pekayon menerapkan bentuk disiplin pelayanan nomor 1. Karena di Puskesmas ini menggunakan nomor antrian, jadi yang lebih dahulu datang, lebih dahulu dilayani sesuai nomor antrian tersebut. Model antrian single channel-multi phase.

Berdasarkan hasil perhitungan yang sudah dilakukan terhadap data pasien BPJS pada Puskesmas Pekayon yang diteliti mulai tanggal 18 November - 16 Desember 2017 antara jam 08.00 - 15.00 WIB.

Tingkat kedatangan rata - rata per jam 8 orang/ jam dan 12 orang, tingkat pelayanan rata - rata 18 orang/jam dan 18 orang/jam.

Ratio pelayanan Puskesmas Pekayon Jaya $44 \%$ dan $70 \%$, probabilitas tidak ada antrian $33 \%$ dan $17,6 \%$. Waktu rata - rata pasien menunggu dalam antrian 3 dan 6 menit. Waktu rata - rata setiap pasien berada dalam system keseluruhan (waktu menunggu plus waktu pelayanan) 7 dan 10 menit.

Kurangnya jumlah loket pendaftaran yang tersedia meskipun data pasien data pasien sudah terkomputerisasi namun pendaftaran masih menggunakan sistem manual serta jumlah pegawai medis yang tidak berimbang dengan jumlah 


\section{DAFTAR PUSTAKA}

Anshory, M. I. (2013, Agustus 22). http://repository.unair.ac.id/1856/. Dipetik Februari 20, 2019, dari UNAIR Repository: http://lib.unair.ac.id

Arikunto, S. (2013). Prosedur Penelitian: Suatu Pendekatan Praktik (15 ed.). Jakarta, DKI Jakarta, Indonesia: Rineka Cipta.

Hillier, F. S., \& J, G. (2001). Introduction to Operation Research (7 ed.). New york, USA: Thomas Cassons.

Larasati, N. (2013, Agustus). Kualitas Pelayanan Program Jaminan Kesehatan Nasional dalam Rangka Menjamin Perlindungan Kesehatan bagi Peserta BPJS di RSUD Dr. M. Soewandhie, Kota Surabaya. Kebijakan dan Manajemen Publik, 4(2), 81-93.

Muslich, M. (2010). Metode Pengambilan Keputusan Kuantitatif (2 ed.). Bandung, Jawa Barat, Indonesia: Bumi Aksara.

Rakhmawati, F., \& Rustiyanto, E. (2016). Analisis Kebutuhan Petugas Rekam Medis Berdasarkan Beban Kerja di Instalasi Rekam Medis RS Aisyiah Muntilan. Jurnal Kesehatan Vokasional, 1(1), 1-8.

Sugiyono. (2011). Metode Penelitian Kuantitatif, Kualitatif dan R\&D. Bandung, Jawa Barat, Indonesia: Alfabeta.

Taha, H. A. (2007). Operations Research an Introduction (8 ed.). New Jersey, USA: Pearson Prentice Hall.

Wati, R. (2017, September). Sistem Antrian Pelayanan Pasien pada Puskesmas Kelurahan Setiabudi Jakarta Selatan dengan Menggunakan Metode Waiting Line. Jurnal Techno Nusa Mandiri, 14(2), 91-96.

\section{Berita}

Warta Kota (2017). Layanan Puskesmas di DKI Belum Sesuai Harapan. Editor : Hertanto Soebijoto. http://wartakota.tribunnews.com/2015/03/31/layananpuskesmas-di-dki-belum-sesuai-harapan

MetroSindoNews (2017). Hanya Dua Puskesmas di Bekasi yang Punya Tenaga Medis dan Prasarana Lengkap. Abdullah M Surjaya. https://metro.sindonews.com/read/1248478/171/hanya-dua-puskesmas-dibekasi-yang-punya-tenaga-medis-dan-prasarana-lengkap-1508054812 